\title{
Terminating red imported fire ants using Cinnamomum osmophloeum leaf essential oil
}

\author{
Sen-Sung Cheng ${ }^{\text {a }}$, Ju-Yun Liu ${ }^{\text {a }}$, Chun-Ya Lin ${ }^{\text {a }}$, Yen-Ray Hsui ${ }^{\mathrm{b}}$, Mei-Chun Lu ${ }^{\mathrm{c}}$, \\ Wen-Jer $\mathrm{Wu}^{\mathrm{c}}$, Shang-Tzen Chang ${ }^{\mathrm{a}, *}$ \\ ${ }^{a}$ School of Forestry and Resource Conservation, National Taiwan University, No. 1, Section 4, Roosevelt Road, Taipei 106, Taiwan \\ ${ }^{\mathrm{b}}$ Division of Silviculture, Taiwan Forestry Research Institute, No. 53, Nan-Hai Road, Taipei 100, Taiwan \\ ${ }^{c}$ Department of Entomology, National Taiwan University, No. 1, Section 4, Roosevelt Road, Taipei 106, Taiwan
}

Received 23 May 2006; received in revised form 12 January 2007; accepted 12 January 2007

Available online 21 March 2007

\begin{abstract}
Eleven compounds from indigenous cinnamon (Cinnamomum osmophloeum) leaf essential oil were identified by GC-MS and the dominant constituent was trans-cinnamaldehyde (79.85\%). The toxicity of leaf essential oil and trans-cinnamaldehyde were then determined to study their effectiveness in controlling the red imported fire ant, Solenopsis invicta Buren. The results of the toxicity tests indicated that both the indigenous cinnamon leaf essential oil and trans-cinnamaldehyde had an excellent inhibitory effect in controlling the red imported fire ant. The $\mathrm{LT}_{50}$ values for both $2 \%$ leaf essential oil and $2 \%$ trans-cinnamaldehyde after open exposure were 105.0 min and $32.2 \mathrm{~min}$; after close exposure were $18.5 \mathrm{~min}$ and $21.2 \mathrm{~min}$, respectively.
\end{abstract}

(C) 2007 Elsevier Ltd. All rights reserved.

Keywords: Solenopsis invicta; Cinnamomum osmophloeum; Essential oil; Leaf; trans-Cinnamaldehyde

\section{Introduction}

The red imported fire ant, Solenopsis invicta Buren, is a voracious consumer of numerous other arthropod species and often is the most abundant predaceous arthropod in crop fields throughout United States, New Zealand, and Australia (Nattrass and Vanderwoude, 2001). It causes almost $\$ 5$ billion losses a year in urban and agricultural areas in the USA. In a large-scale invasion that has never been seen before, the spread of red imported fire ant in Taiwan increased at an alarming rate in the year of 2004. In general, the control of red imported fire ants is usually accomplished by using baits or traditional insecticides, such as pyrethroid or organophosphate, both contribute significantly to human health and environmental pollution. These problems have called for the need for new strategies

\footnotetext{
* Corresponding author. Tel.: +88623366 4626; fax: +886223654520. E-mail address: peter@ntu.edu.tw (S.-T. Chang).
}

in red imported fire ant control. As a result, the search for natural, safe and none polluting insecticides is starting to attract a lot of attention, and many efforts have been focused on exploring bioactive chemical compounds from plants (Appel et al., 2004; Vogt et al., 2002; Cheng et al., 2004a).

Indigenous cinnamon (Cinnamomum osmophloeum Kaneh.) (Cinnamomum) is an endemic tree that grows in Taiwan's natural hardwood forests at elevations between 400 and $1500 \mathrm{~m}$ (Liu et al., 1988). C. osmophloeum has been of interest to researchers because the chemical constituents of its leaf essential oil are similar to those of the famous Cinnamomum cassia bark oil (Chang et al., 2001; Hu et al., 1985). Cinnamon oil is commonly used in the food industry for its special aroma. In addition, its antimicrobial and antifungal properties have also drawn great attention from many researchers (Chang et al., 2001; Hili et al., 1997; Kim et al., 2004; Singh et al., 1995). Our previous studies demonstrated that leaf essential oils from cinnamaldehyde type of $C$. osmophloeum had excellent antitermite, 
antibacterial, antimite, antimosquito, antipathogenic and antifungal properties (Chang et al., 2001; Chang and Cheng, 2002; Chen et al., 2002; Cheng et al., 2004b; Cheng et al., 2006; Lee et al., 2005; Wang et al., 2005). In this study, leaf essential oil from C. osmophloeum was analyzed using GC-MS for its chemical composition and the toxicity of indigenous cinnamon leaf essential oil and trans-cinnamaldehyde were determined to evaluate the effectiveness of both in controlling the red imported fire ant.

\section{Methods}

\subsection{Insect}

Workers of red imported fire ants were reared in the Department of Entomology, National Taiwan University in Taiwan. Workers and nest material were placed in glass column bottle $(20 \mathrm{~cm}$ diameter $\times 30 \mathrm{~cm})$ and the bottle was then coated with Teflon emulsion on the top. The nest material was held at $25-27^{\circ} \mathrm{C}$ and a photoperiod alternating between 12-h in light and 12-h in the dark at $80 \pm 5 \%$ RH. A $10 \%$ sucrose solution, dead crickets, and peanut butter were used as the growth media.

\subsection{Collection of essential oil from C. osmophloeum leaf}

The leaves from a 12-year-old C. osmophloeum were collected in September, 2002 from Da-Pin-Ting of the Taiwan Sugar Farm located in Nantou county in central Taiwan. The species was identified by Mr. Yen-Ray Hsui of the Taiwan Forestry Research Institute, and the voucher specimen (CO1001) was deposited at the laboratory of wood chemistry, School of Forestry and Resource Conservation, National Taiwan University. Fresh leaf essential oil from C. osmophloeum was obtained using water distillation in a Clevenger-type apparatus for $6 \mathrm{~h}$ (Chang et al., 2001) and their constituents were determined by gas chromatography-mass spectrometry.

\subsection{Gas chromatography-mass spectrometry analysis}

The mass spectrometer was equipped with a PoLaris Q mass selective detector in electron impact (EI) ionization mode $(70 \mathrm{eV})$. A Trace GC Ultra was used and operated under the following conditions: a DB-5MS capillary column $(5 \%$ phenyl methylpolysiloxane, $30 \mathrm{~m} \times 0.25 \mathrm{~mm}$; film thickness $0.25 \mu \mathrm{m}$ ) was held at $50^{\circ} \mathrm{C}$ for $2 \mathrm{~min}$, then raised to $250{ }^{\circ} \mathrm{C}$ at the rate of $5{ }^{\circ} \mathrm{C} / \mathrm{min}$, and held for $5 \mathrm{~min}$; helium carrier gas was used and held at the flow rate of $1.0 \mathrm{ml} / \mathrm{min}$; the split ratio was kept at 1:60. Diluted samples $(1.0 \mu 1,1 / 100, v / v$, in ethyl acetate) were injected manually in split mode. The ion source temperature was set at $200{ }^{\circ} \mathrm{C}$, and the injector temperature was set at $270{ }^{\circ} \mathrm{C}$. The sector mass analyzer was set to scan from 50 to $650 \mathrm{amu}$ every $0.5 \mathrm{~s}$. The Kovats retention indices were calculated for all volatile constituents using a homologous series of $n$-alkanes $\mathrm{C}_{9}-\mathrm{C}_{15}$ on DB-5MS column.
Quantification was performed using percentage peak area calculations and the identification of individual components was done using the NIST MS Search 2.0, literature (Adams, 2001), and several authentic reference compounds.

\subsection{Isolation and identification}

One active component (9.04 min retention time) was isolated and purified from C. osmophloeum leaf essential oil by semipreparative HPLC on a model L-7150 instrument (Hitachi, Japan) with a $250 \times 10 \mathrm{~mm}$ i.d., $5 \mu \mathrm{m}$ Luna Silica (2) (Phenomenex, American) column, ethyl acetate/hexane (15:85) mobile phase, $4.0 \mathrm{ml} / \mathrm{min}$ flow rate, and Hitachi L-7490 RI detector. Structural determination of the compound isolated was made by spectroscopic analyses, including UV spectrum was recorded with a Jasco V-550 spectrometer, IR spectrum was obtained from a Bio-Rad FTS-40 spectrometer, Electron impact mass spectrometer (EIMS) data was obtained on a Finnigan MAT-95S mass spectrometer, ${ }^{1} \mathrm{H}$ and ${ }^{13} \mathrm{C}$ NMR spectra were recorded on a Bruker Avance 500 spectrometer at $500 \mathrm{MHz}$, and by direct comparison with an authentic reference compound, and it was characterized as trans-cinnamaldehyde on the basis of the data from the literature (Lee et al., 2002). The compound was identified on the basis of the following evidence: UV (EtOH), $\lambda_{\max }: 285 \mathrm{~nm}$. IR $(\mathrm{KBr}), \mathrm{cm}^{-1}: 2925$, 2816, 2744, 1682, 1625, 1574, 1450, 1123, 748, 690. EIMS $(70 \mathrm{eV}), \mathrm{m} / z$ (relative intensity) for $\mathrm{C}_{9} \mathrm{H}_{8} \mathrm{O}$ found 132 , $\mathrm{M}^{+} 132$ (59), 131 (100), 103 (50), 77 (35), 51 (23). ${ }^{1} \mathrm{H}$ NMR $\left(\mathrm{CD}_{3} \mathrm{OD}, 500 \mathrm{MHz}\right) \delta 6.67(\mathrm{dd}, 1 \mathrm{H}, J=7.7$ and $16 \mathrm{~Hz}, \mathrm{H}-8), 7.45$ (d, $1 \mathrm{H}, J=16 \mathrm{~Hz}, \mathrm{H}-7), 7.41(\mathrm{dd}, 1 \mathrm{H}$, $\mathrm{H}-4), 7.40-7.41$ (m, 2H, H-2 and H-6), 7.53-7.55 (m, 2H, $\mathrm{H}-3$ and $\mathrm{H}-5), 9.67$ (d, $1 \mathrm{H}, J=7.7 \mathrm{~Hz}, \mathrm{H}-9) ;{ }^{13} \mathrm{C}$ NMR $\left(\mathrm{CD}_{3} \mathrm{OD}, 500 \mathrm{MHz}\right) \delta 193.6$ (C-9), 152.7 (C-7), 133.9 (C1), 131.2 (C-4), 129.0 (C-2 and C-6), 128.5 (C-8), 128.4 (C-3 and C-5).

\subsection{Constituents of essential oil}

The following compounds of essential oil constituents were purchased from Acros (Belgium): benzadehyde, benzenpropanal, eugenol, L-bornyl acetate, and cinnamyl acetate. $p$-Allylanisole and $\beta$-caryophyllene were purchased from TCI (Japan). trans-Cinnamaldehyde was isolated from C. osmophloeum leaf essential oil.

\subsection{Open and close exposure toxicity tests}

The method of Appel et al. (2004) was modified slightly and used to determine the effectiveness of controlling the red imported fire ant. Beakers of $10 \mathrm{~cm}$ diameter bottoms were used for both the open and close exposure toxicity tests. The inside vertical wall of each beaker was coated with Teflon emulsion and allowed to dry to prevent the red imported fire ants from escaping and to force the red imported fire ants onto granules placed on the bottom. 
For the open exposure toxicity test, 20 workers of red imported fire ants were transferred into a beaker, followed by spraying EtOH solution containing C. osmophloeum leaf essential oil or trans-cinnamaldehyde into the beaker. The red imported fire ants sprayed with $C$. osmophloeum leaf essential oil or trans-cinnamaldehyde were uncovered and exposed to the air. For the close exposure toxicity tests, groups of 20 workers were placed in a beaker, followed by spraying EtOH solution containing essential oil or trans-cinnamaldehyde in the beaker. The beakers were covered so they were not exposed to the air. Essential oil or trans-cinnamaldehyde was tested at the concentrations of $2 \%, 1 \%$ and $0.5 \%$ in EtOH. The ants in the control beaker were only sprayed by EtOH solution that did not contain any essential oil or trans-cinnamaldehyde. Each test was replicated three times.

Mortality was recorded every $10 \mathrm{~min}$ for a total of $90 \mathrm{~min}$ for the close exposure toxicity tests and every $30 \mathrm{~min}$ for $3 \mathrm{~h}$ for the open exposure toxicity tests. During the tests no food was given to the fire ants. Percent mortality was corrected for control mortality using Abbott's formula, and the results were plotted on log probability paper using the method of Finney (1971). Toxicity and activity were reported as $\mathrm{LT}_{50}$, the time it took, in min, to cause $50 \%$ fire ant mortality.

\subsection{Statistical analyses}

Percent of fire ant mortality was determined and transformed to arcsine square-root values for analyses of variance (ANOVA). Treatment means were compared and separated using the Scheffe test at $P=0.05$. The means $( \pm \mathrm{SE})$ of untransformed data are reported.

\section{Results and discussion}

\subsection{Chemical compositions of essential oil}

Distillation of $C$. osmophloeum leaves yielded about $1.02 \%(\mathrm{w} / \mathrm{w})$ essential oil based on dry weight. The results of GC-MS analyses of the C. osmophloeum leaves essential oil are compiled and shown in Table 1. It shows that the essential oil contain eleven compounds representing $99.16 \%$ of the essential oils. trans-Cinnamaldehyde with a yield of $79.85 \%$ is the dominant constituent that matches the finding in our previous classification (Cheng et al., 2004b) that the leaf essential oil from the C. osmophloeum was in the class of cinnamaldehyde and the percentage distribution of essential oil in the leaves of C. osmophloeum are similar to that reported by Fang et al. (1989) and Cheng et al. (2004b, 2006).

\subsection{Open and close exposure toxicity of essential oil}

The toxicities of indigenous cinnamon leaf essential oil after close exposure and open exposure were determined for controlling the red imported fire ant (Figs. 1 and 2).
Table 1

Chemical compositions of leaf essential oil from C. osmophloeum

\begin{tabular}{llrrrl}
\hline No. & Compounds & RT $^{\mathrm{a}}$ & $\mathrm{KI}^{\mathrm{b}}$ & $\begin{array}{l}\text { Peak area } \\
(\%)\end{array}$ & Identification $^{\mathrm{c}}$ \\
\hline 1 & Benzaldehyde & 8.12 & 961 & 5.35 & $\mathrm{MS}, \mathrm{KI}, \mathrm{CO}$ \\
2 & Benzenepropanal & 14.00 & 1163 & 7.00 & $\mathrm{MS}, \mathrm{CO}$ \\
3 & $p$-Allylanisole & 15.07 & 1198 & 1.61 & $\mathrm{MS}, \mathrm{CO}$ \\
4 & cis-Cinnamaldehyde & 15.63 & 1219 & 1.91 & $\mathrm{MS}, \mathrm{KI}$ \\
5 & 4-Allylphenol & 16.68 & 1258 & 0.22 & $\mathrm{MS}$ \\
6 & trans- & 17.06 & 1271 & 79.85 & $\mathrm{MS}, \mathrm{KI}, \mathrm{CO}$ \\
& Cinnamaldehyde & & & & \\
7 & L-Bornyl acetate & 17.56 & 1289 & 1.11 & $\mathrm{MS}, \mathrm{KI}, \mathrm{CO}$ \\
8 & Eugenol & 19.43 & 1360 & 1.13 & $\mathrm{MS}, \mathrm{KI}, \mathrm{CO}$ \\
9 & $\alpha$-Cubebene & 20.03 & 1382 & 0.17 & $\mathrm{MS}, \mathrm{KI}$ \\
10 & $\beta$-Caryophyllene & 21.18 & 1426 & 0.19 & $\mathrm{MS}, \mathrm{KI}, \mathrm{CO}$ \\
11 & Cinnamyl acetate & 21.66 & 1446 & 0.62 & $\mathrm{MS}, \mathrm{KI}, \mathrm{CO}$ \\
\multicolumn{2}{l}{ Identified components (\%) } & & & 99.16 & \\
Yield (\%) & & & 1.02 & \\
\hline
\end{tabular}

${ }^{\mathrm{a}}$ Retention time (min).

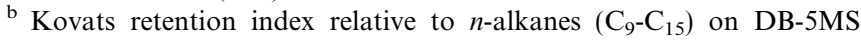
column.

${ }^{c}$ MS, by comparison of the mass spectrum with those of the computer mass libraries; KI, by comparison of Kovats retention index with those from the literature (Adams, 2001); CO, identified by co-injection of an authentic sample.

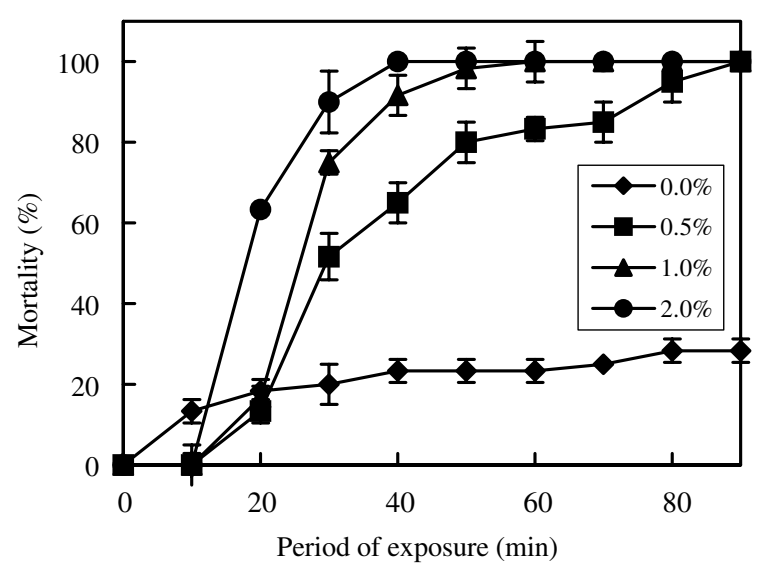

Fig. 1. Mortality of red imported fire ant after close exposure to $C$. osmophloeum leaf essential oil. Each data point represents mean \pm SE of three replicate cups each containing 20 ants.

Fig. 1 shows that $2.0 \%$ indigenous cinnamon leaf essential oil terminated red imported fire ant completely after $40.0 \mathrm{~min}$ and the $\mathrm{LT}_{50}$ value was $18.5 \mathrm{~min}$ (Table 2) in the close exposure tests, indicating that it has the strongest toxicity against red imported fire ant. When concentration decreased to $1.0 \%$ and $0.5 \%$, the indigenous cinnamon leaf essential oil induced $100 \%$ mortality of red imported fire ant after $60.0 \mathrm{~min}$ and $90.0 \mathrm{~min}$, respectively. Their $\mathrm{LT}_{50}$ values were $24.2 \mathrm{~min}$ and $31.3 \mathrm{~min}$, respectively (Table 2). The mortality of the control was $28.3 \%$ after $90.0 \mathrm{~min}$ against red imported fire ant, showing that EtOH did have a low toxicity effect. In the open exposure tests, the mortality of cinnamon leaf essential oil against red imported fire ant after $180 \mathrm{~min}$ was $3.3 \%\left(\mathrm{LT}_{50}>180.0 \mathrm{~min}\right), 6.7 \%$ 


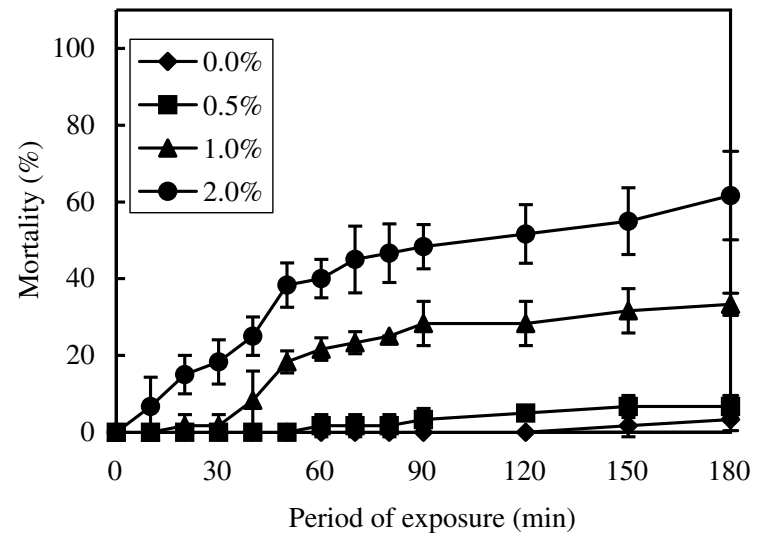

Fig. 2. Mortality of red imported fire ant after open exposure to $C$. osmophloeum leaf essential oil. Each data point represents mean $\pm \mathrm{SE}$ of three replicate cups each containing 20 ants.

Table 2

$\mathrm{LT}_{50}(\mathrm{~min})$ values of red imported fire ant after close and open exposures to C. osmophloeum leaf essential oil and trans-cinnamaldehyde

\begin{tabular}{lrrrrr}
\hline Concentration (\%) & \multicolumn{2}{l}{ Leaf essential oil } & & \multicolumn{2}{c}{ trans-Cinnamaldehyde } \\
\cline { 2 - 3 } \cline { 6 - 6 } & \multicolumn{1}{l}{ Open } & Close & & Open & Close \\
\hline 0 & $>180.0$ & $>90.0$ & & $>180.0$ & $>90.0$ \\
0.5 & $>180.0$ & 31.3 & $>180.0$ & 39.5 \\
1.0 & $>180.0$ & 24.2 & & 64.8 & 31.0 \\
2.0 & 105.0 & 18.5 & & 32.2 & 21.2 \\
\hline
\end{tabular}

$\left(\mathrm{LT}_{50}>180.0 \mathrm{~min}\right), 33.3 \%\left(\mathrm{LT}_{50}>180.0 \mathrm{~min}\right)$, and $61.7 \%$ $\left(\mathrm{LT}_{50}=105.0 \mathrm{~min}\right)$ at the concentration of $0 \%, 0.5 \%$, $1.0 \%$, and $2.0 \%$, respectively (Fig. 2; Table 2). Similar results have been observed in the Appel et al. (2004) study; the $\mathrm{LT}_{50}$ value of $2.0 \%$ mint oil granules $\left(164.81 \mathrm{mg} / \mathrm{cm}^{2}\right)$ was $1.2 \mathrm{~h}$ in continuous exposure. These results indicate that leaf essential oil provided higher inhibitory performance against red imported fire ant in the closed exposure than in the open exposure.

\subsection{Open and close exposure toxicity of trans-cinnamaldehyde}

Since leaf essential oil contained a higher amount of trans-cinnamaldehyde (Table 1) and it also displayed strong toxicity, it is clear that the mortality of red imported fire ant of leaf essential oil is directly affected by the trans-cinnamaldehyde content. The results of trans-cinnamaldehyde after close exposure and open exposure were reported in Figs. 3 and 4 . In the close exposure tests, $0.5 \%, 1.0 \%$, and $2.0 \%$ of trans-cinnamaldehyde killed all red imported fire ants after $90.0 \mathrm{~min}, 70 \mathrm{~min}$, and $50.0 \mathrm{~min}$, respectively (Fig. 3), indicating that trans-cinnamaldehyde has the strongest toxicity against red imported fire ant. As seen in Fig. 4, 2.0\% transcinnamaldehyde terminated all red imported fire ant in the open exposure tests after $80.0 \mathrm{~min}$, followed by $1.0 \%$ trans-cinnamaldehyde $(180 \mathrm{~min})$. The mortality of $0.5 \%$ trans-cinnamaldehyde was only $18.3 \%$ after $180.0 \mathrm{~min}$

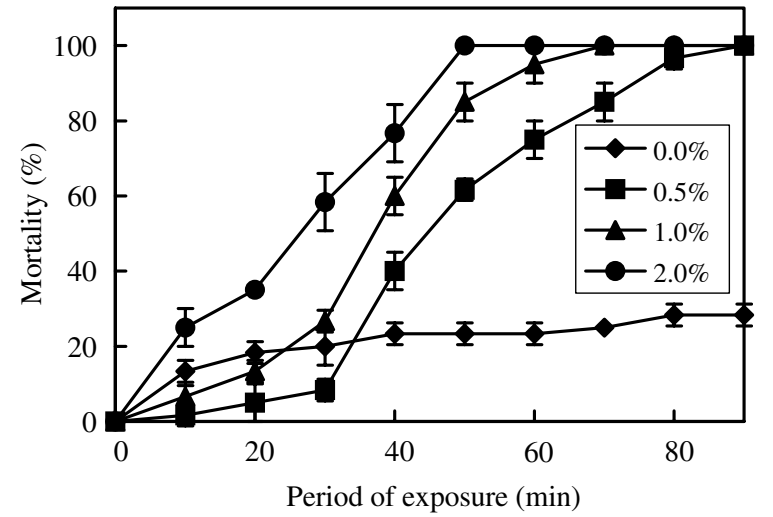

Fig. 3. Mortality of red imported fire ant after close exposure to transcinnamaldehyde. Each data point represents mean $\pm \mathrm{SE}$ of three replicate cups each containing 20 ants.

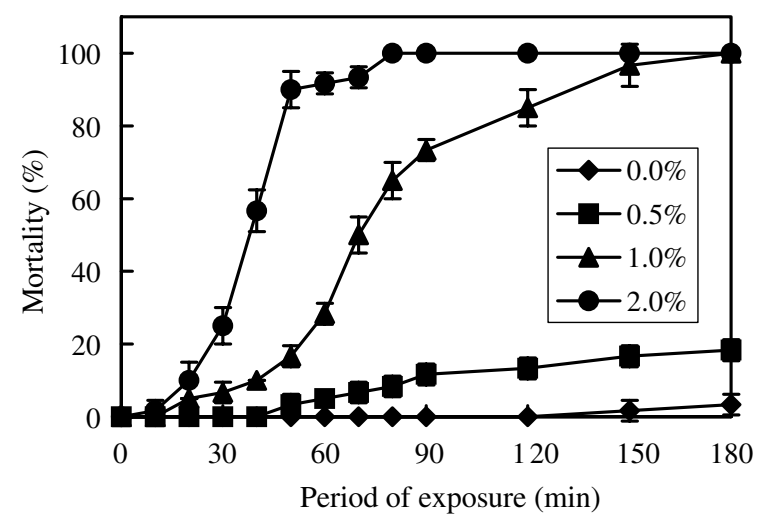

Fig. 4. Mortality of red imported fire ant after open exposure to transcinnamaldehyde. Each data point represents mean $\pm \mathrm{SE}$ of three replicate cups each containing 20 ants.

showing that $0.5 \%$ is too diluted to have an effective termination effect.

Comparing the $\mathrm{LT}_{50}$ values of trans-cinnamaldehyde after open and close exposures as shown in Table 2, it indicated that $2.0 \%$ trans-cinnamaldehyde exhibited the strongest termination activity with a $\mathrm{LT}_{50}$ value of $32.2 \mathrm{~min}$ (open exposure) and $21.2 \mathrm{~min}$ (close exposure), followed by $1.0 \%$ trans-cinnamaldehyde $\left(\mathrm{LT}_{50}=64.8 \mathrm{~min}\right.$ and $31.0 \mathrm{~min})$, and $0.5 \%$ trans-cinnamaldehyde $\left(\mathrm{LT}_{50}>\right.$ $180.0 \mathrm{~min}$ and $=39.5 \mathrm{~min}$ ). It is therefore proven that trans-cinnamaldehyde is responsible for the excellent termination effect against red imported fire ant using leaf essential oil.

\section{Conclusions}

The leaf essential oil of C. osmophloeum exhibits effective toxicity in both open exposure and close exposure against red imported fire ant. The major component in the essential oil is trans-cinnamaldehyde and it plays the key role in controlling the red imported fire ant. As a conclusion, both indigenous cinnamon leaf essential oil and trans-cinnamaldehyde are effective and environmentally benign agents in red imported fire ant control. 


\section{Acknowledgements}

We would like to thank Mrs. Hou-Ling Huang (Department of Chemistry, National Taiwan University) for NMR spectral analyses and the Taiwan Da-Pin-Ting Sugar Farm for providing C. osmophloeum material.

\section{References}

Adams, R.P., 2001. Identification of Essential Oil Components by Gas Chromatography/Quadrupole Mass Spectroscopy. Illinois, Allured.

Appel, A.G., Gehret, M.J., Tanley, M.J., 2004. Repellency and toxicity of mint oil granules to red imported fire ants (Hymenoptera: Formicidae). J. Econ. Entomol. 97, 575-580.

Chang, S.T., Chen, P.F., Chang, S.C., 2001. Antibacterial activity of leaf essential oils and their constituents from Cinnamomum osmophloeum. J. Ethnopharmacol. 77, 123-127.

Chang, S.T., Cheng, S.S., 2002. Antitermitic activity of leaf essential oils and components from Cinnamomum osmophloeum. J. Agric. Food Chem. 50, 1389-1392.

Chen, P.F., Chang, S.T., Wu, H.H., 2002. Antimite activity of essential oils and their components from Cinnamomum osmophloeum. Quart. J. Chin. For. 35, 397-404.

Cheng, S.S., Wu, C.L., Chang, H.T., Kao, Y.T., Chang, S.T., 2004a. Antitermitic and antifungal activity of essential oil of Calocedrus formosana leaf and its composition. J. Chem. Ecol. 30, 19571967.

Cheng, S.S., Liu, J.Y., Tsai, K.H., Chen, W.J., Chang, S.T., 2004b. Chemical composition and mosquito larvicidal activity of essential oils from leaves of different Cinnamomum osmophloeum provenances. J. Agric. Food Chem. 52, 4395-4400.

Cheng, S.S., Liu, J.Y., Hsui, Y.R., Chang, S.T., 2006. Chemical polymorphism and antifungal activity of essential oils from leaves of different provenances of indigenous cinnamon (Cinnamomum osmophloeum). Bioresour. Technol. 97, 306-312.
Fang, J.M., Chen, S.A., Cheng, Y.S., 1989. Quantitative analysis of the essential oil of Cinnamomum osmophloeum. J. Agric. Food Chem. 37, 744-746.

Finney, D.J., 1971. Probit Analysis, third ed. Cambridge University Press, London, UK.

Hili, P., Evans, C.S., Veness, R.G., 1997. Antimicrobial action of essential oils: the effect of dimethylsulphoxide on the activity of cinnamon oil. Lett. Appl. Microbiol. 24, 269-275.

Hu, T.W., Lin, Y.T., Ho, C.K., 1985. Natural variation of chemical components of the leaf oil of Cinnamomum osmophloeum Kaneh. Bull. Taiwan For. Res. Inst. Eng. 78, 296-313.

Kim, H.O., Park, S.W., Park, H.D., 2004. Inactivation of Escherichia coli O157:H7 by cinnamic aldehyde purified from Cinnamomum cassia shoot. Food Microbiol. 21, 105-110.

Lee, H.S., Kim, Y.S., Kim, M.K., 2002. Suppression effect of Cinnamomum cassia bark-derived component on nitric oxide synthase. J. Agric. Food Chem. 50, 7700-7703.

Lee, H.C., Cheng, S.S., Chang, S.T., 2005. Antifungal property of the essential oils and their constituents from Cinnamon osmophloeum leaf against tree pathogenic fungi. J. Sci. Food Agric. 85, 2047-2053.

Liu, Y.C., Lu, F.Y., Ou, C.H., 1988. Trees of Taiwan Monographic Public No. 7 College of Agriculture. National Chung-Hshing University, Taichung, Taiwan, p. 136.

Nattrass, R., Vanderwoude, C., 2001. A preliminary investigation of the ecological effects of red imported fire ants (Solenopsis invicta) in Brisbane. Ecol. Manage. Rest. 2, 220-223.

Singh, H.B., Srivastava, M., Singh, A.B., Srivastava, A.K., 1995. Cinnamon bark oil, a potent fungitoxicant against fungi causing respiratory tract mycoses. Allergy 50, 995-999.

Vogt, J.T., Shelton, T.G., Merchant, M.E., Russell, S.A., Tanley, M.J., Appel, A.G., 2002. Efficacy of three citrus oil formulations against Solenopsis invicta Buren (Hymenoptera: Formicidae), the red imported fire ant. J. Agric. Urban Entomol. 19, 159-171.

Wang, S.Y., Chen, P.F., Chang, S.T., 2005. Antifungal activities of essential oils and their constituents from indigenous cinnamon (Cinnamomum osmophloeum) leaves against wood decay fungi. Bioresour. Technol. 96, 813-818. 